Balancing Autonomy Rights and Protection: Children's Involvement in a Child Safety Online Project

Suzanne Ost

Lancaster University

Address:

Law School

Bowland North

Lancaster University

Lancaster

LA1 4YN

Email: $\underline{\text { s.ost @lancaster.ac.uk }}$

Telephone: 01524594938

Author biography: Dr Suzanne Ost is a senior lecturer in law at Lancaster University. Her main research interests are the legal and societal responses to child pornography and the sexual grooming of children, research ethics and health-care law and ethics. 


\title{
Balancing Autonomy Rights and Protection: Children's Involvement in a Child Safety Online Project
}

\begin{abstract}
Researchers who involve children in their research are faced with the challenge of choosing between differing theoretical approaches which can prioritise children's autonomy rights or their 'vulnerability' and their need to be protected. Somewhat confusingly, ethical guidelines seem to reflect a combination of these approaches. Even when researchers have settled on their preferred approach, they may find that this then has to be modified in accordance with gatekeeper requirements. In the context of children's involvement in a child safety online project, this paper highlights the difficulties encountered because of a tension between children's autonomy rights, educational norms in a school setting and child protection concerns, and considers whether an appropriate balance was achieved.
\end{abstract}

\section{Introduction}

Research involving human participants inevitably raises numerous ethical and legal issues. These issues are intensified when the participants are children, a 'vulnerable' research participant group (Biggs, 2010: 117-128), and when such research occurs in a school setting and involves the application of new software technologies which themselves raise further ethical concerns. This is the backdrop to the Isis project, ${ }^{1}$ which involves the development of a software package to assist law enforcement agencies in protecting children online. One of the anticipated end products of the project is a tool 
that will enable law enforcement agencies to detect adults masquerading as children in online communications. In order to develop this tool, it is necessary to create language profiles for children and adults. Language data has thus been gathered from both groups and some of this data has been acquired from child participants chatting online in an educational research activity forming part of the project.

The rationale for the project - that more needs to be done to enhance children's safety online and this might be achieved by developing a software tool to assist law enforcement agencies - is surely legitimate, albeit not without points of contention. For example, the choice of focus might give the impression that child safety online should be prioritised over measures to improve child protection in the 'real' world. But when it comes to the matter of children's involvement in the research, the nature of the project's protective aim and certain educational norms in a school setting may pose problems. They could have the effect of prioritising parental decision-making and perceptions of children as being in need of protection rather than as individuals who possess autonomy and empowerment rights. This places obstacles in the way of researchers adopting a theoretical approach to involving children in research that sees children as social actors. Thus it may be harder for researchers to take 'ethical symmetry' between adults and children as their starting point (Christensen and Prout, 2002).

In what follows, I will first outline the differing theoretical approaches to involving children in research, the ethical guidelines and the applicable law. I will then discuss the Isis project and explicate the approach it has taken. In particular, I will highlight the difficulties encountered because of a tension between children's autonomy rights, 
educational norms in a school setting and child protection concerns, and consider whether an appropriate balance was achieved.

\section{Ethical guidelines, differing theoretical approaches to involving children in research and relevant law}

All research involving human participants raises important ethical concerns relating to participants' dignity, well-being and confidentiality and obtaining their informed consent (Biggs, 2010, p. 3). But there are added ethical and legal concerns where research involves the participation of children, a research group categorised as 'vulnerable' (Flaskerud and Winslow, 1998). Consequently, children's charities, welfare organisations and professional associations have developed research ethics guidance and policies (eg, British Educational Research Association, 2004: NCB, 2003; NSPCC, 2009; Society for Research in Child Development, 2007), and there is now a significant amount of academic literature on research ethics and children (eg, Alderson and Morrow, 2004; Green and Hogan, 2005; Fraser and others, 2004). Alongside such guidance, differing theoretical perspectives on involving children in research exist (Christensen and Prout, 2002). These involve constructing children as (1) objects of research (emphasising their vulnerability and assumed dependency on adults); (2) subjects (although recognition of their subjectivity is 'conditioned by judgements about their cognitive abilities and social competencies' (Christensen and Prout, 2002, p. 41); (3) social actors with autonomy rights; (4) active participants in research. These perspectives may conflict and enjoy increasing and decreasing popularity across time and space. Whilst the 'children as social actors' approach is most often reflected in the 
contemporary literature, it can be difficult to ensure that research intended to fit this approach actually does so, because of firmly entrenched power relationships between adults and children (Christensen and Prout, 2002, p. 484).

Significantly, it is a mixture of these theoretical approaches that appears to be reflected in the relevant guidelines. For instance, guidelines recognise children's autonomy rights, yet also evidence a perception that children's capacities to understand are of a different level than adults' (see eg, BSA 2002, para 30) - a 'children as subjects' approach. At the same time, guidelines highlight the significance of ensuring children's welfare and protecting them from harm, an approach which bears more resemblance to the 'children as objects' perspective. Thus, on the matter of confidentiality, whilst the child's right to confidentiality is recognised (see eg, Society for Research in Child Development, 2007, Principle 12), the limitations placed on this by the demands of child protection are also emphasised. According to the NSPCC, 'the privacy of participants should be respected in all cases except when... confidentiality cannot be promised because ongoing abuse of a child cannot be kept secret' (NSPCC, 2009, principle 3 ). If a child reveals information that indicates s/he is potentially at harm, there is an assumption that the researcher has a duty to pass this information on to an appropriate person (Morrow and Richards, 1996, p. 97; NCB, 2003, p 3). Guidelines and academic authors advise that researchers should first discuss the matter with the child (NCB, 2003; Morrow and Richards, 1996). Then, if 'after discussion with the child, the researcher decides it is necessary to inform others - hopefully with the consent of the child - the researcher must ensure that the child has immediate support and is kept fully informed' (NCB, 2003, p. 3). The use of the word 'hopefully' here is instructive; 
whilst ideally, the child will consent, if s/he does not, the need to respect the child's autonomy rights is clearly overridden by child protection concerns.

It appears, therefore, that whilst the guidelines start from a position of perceiving children as subjects with autonomy rights, the 'children as objects' approach is then adopted and prioritised if a child is considered to be at risk of harm. This reflects the general legal position regarding children: the courts have special regard for 'the ascertainable wishes and feelings of the child concerned' considered in the light of her/his age and understanding and the growing autonomy of children is recognised (Axon v. Secretary of State for Health and the Family Planning Association [2006] EWCA 37). However, the welfare principle continues to dominate law and policy surrounding children in the UK (Children Act 1989).

On the matter of consent, in the case of a very young child, some guidelines state that parents or carers rather than the child may hold the only 'key' to the door of consent (NCB, 2009, p. 3). Even in the case of an older child, some guidelines suggest that consent might be requried from the individual with parental responsibility for him/her, although this should be in addition to, rather than an alternative to, consent from the child (NCB, 2009). Interestingly, NCB Researchers would normally seek parental or carer consent in the case of any children under the age of sixteen (NCB, 2009). More commonly, other guidelines emphasise that when children possess 'sufficient understanding and intelligence to understand what is proposed', then consent should be sought from them rather than their parents (Royal College of Paediatrics, 2000, p. 180). All the guidelines I have referred to emphasise that the consent provided by child participants in research must be informed (eg, NSPCC, 2009, principle 2). What is 
considered to be crucial is ensuring the child's understanding so that $\mathrm{s} /$ he can make an informed decision as to whether or not to take part. The level of information that should be given and the language in which this needs to be provided is ascertained on the basis of the age and understanding of the participants, an appoach which again reflects a 'children as subjects' perspective.

Some guidelines suggest that if the child does not have the decision making capacity to provide informed consent, obtaining assent from the child and informed consent from the parent may be the most appropriate way forward (Society for Research in Child Development, 2007, Principle 2). Yet approaching the matter on the basis of assent rather than consent gives the impression that children's capabilities to give informed consent are necessarily limited. This may encourage researchers to opt for achieving a lower level of participant understanding and does not promote ethical symmetry between adults and children (Christensen and Prout, 2002). No such 'middle line' between capacity to give consent and incapacity exists within the law on children's medical treatment - a competent 'mature minor' has the right to consent to medical treatment and if s/he is not competent to do so, consent rests with the parents (Gillick $v$. West Norfolk and Wisbech AHA [1985] 3 All ER 402). Moreover, the validity of any assent that, by its nature, would only reveal a participant's partial comprehension of the research and her/his involvement, can surely be questioned (Alderson and Morrow, 2004, p. 97). Notwithstanding this, there may be circumstances in which informed consent from children is perceived as being less of an ethical imperative. If the research has educational elements and occurs in school as part of pupils' normal classroom activities, this educational framing may mean that different norms apply (Edwards and Fowler, 2007), norms which are more in line with the 'children as objects' perspective. 
Turning to the law, domestic legislation relating to privacy and confidentiality is applicable in the context of research involving children. The Human Rights Act 1998 (HRA), which incorporated the European Convention on Human Rights (ECHR) into domestic law, makes it unlawful for a public authority to act incompatibly with a Convention right (s.6(1)). A university is classed as a public authority. Thus, where research is being conducted by university employees, there is a direct obligation under the HRA to comply with ECHR rights. The most relevant of the ECHR rights here is Article $8(1)$ which protects the right to private and family life and a broader right to personal autonomy (Pretty $v$ DPP [2002] 1 AC 800, 818). Article 8(1) applies equally to children as to adults (Murray v Express Newspapers plc and another [2008] 3 WLR 1360). It does not provide an absolute right, however, and an individual's right to privacy can be justifiably violated by the state on numerous grounds, some of which relate to the public interest and to the rights and freedoms of others (Article 8(2)).

Where a research project involves the processing of personal data, then the provisions of the Data Protection Act 1998 (DPA) must be complied with. Personal data is information relating to a living individual from which s/he can be identified or could be identified from if it is combined with other information held by the data controller (DPA, s.1(2)). The DPA contains strict requirements for the processing of such data and provides the subject with access rights to this data. If, however, the data gathered in a research project is anonymised so that personal identifiers are removed, then the DPA does not apply because this no longer constitutes 'personal data' (Durant v Financial Services Authority [2004] FSR 28). 
Given the legal requirements, ethical challenges and often conflicting theoretical approaches identified here, there is a danger that researchers will steer away from involving children in research with the effect that important research that could benefit children is not carried out (Alderson and Morrow, 2004, p. 31). But particularly with the advent of the UN Convention of the Rights of the Child (UNCRC), children's involvement in research projects can be framed as a right to participation issue (NCB, 2009, p. 2). Indeed, Articles 12 and 13 of the UNCRC suggest that, as a matter of right, children be enabled to participate in research (see also NSPCC, 2009, principle 6). Whilst more recently, there has been extensive critique of the idea that participatory research involving children is ethically superior to other forms of research (Holland and others, 2010), adopting methodologies that enable children to interpret their own data continues to be seen as an important way to recognise children as social actors and engage them in the research process.

It is thus clear that whilst there is a wealth of ethical guidance and academic literature surrounding children's involvement in research, theoretical perspectives differ. Researchers face the difficult task of deciding which to adopt and ensuring that their methodologies are appropriate to their choice and comply with the law. As Cree, Kay and Tisdall have observed, 'The question remains: how far have the developing theoretical, legal/policy and ethical frameworks for research with children stood up to testing in practical... research?' (Cree and others, 2002, p. 48). I will now consider this matter in the context of the Isis project.

\section{The Isis Project}


The Isis project is developing an ethics-centred monitoring framework and toolkit to support law enforcement agencies in protecting children online. ${ }^{2}$ One of the project's aims is to create a tool that enables the identification of adults masquerading as children in online social networks and chat rooms in order to gain children's trust and thereby initiate a sexual grooming process (Hughes and others, 2008). ${ }^{3}$ Given the nature of communications that occur via online social networks and chat applications, such deception cannot be spotted by analysing body language or tone of voice, as might be possible in the case of face to face or telephone communications (Hughes and others, 2008). The language used in online communications can thus be a crucial key to identifying adults pretending to be children.

The project utilises natural language analysis techniques originating from computational and corpus-based linguistics (Walkerdine and others, 2009). Language profiles for children and adults have been created which allow for the differentiation of 'child chat' and 'adult chat' through the gathering of language data from both groups. The child language data was gathered from child participants chatting online in studies forming part of the project and children's online chat data from a corpus consisting of posts from online chat services. The resulting corpora of child and adult language can be compared with observed chat data using natural language analysis techniques and this is how the tool could be used by law enforcement agents in identifying adults pretending to be children. Even if an adult tries to adopt child chat terminology, the tool should still be able to detect their true adult status in most cases since the fine-grained statistical analysis looks at the way in which the individual is actually using language, taking into account punctuation, capital letters and syntax. 
The project researchers have endeavoured to use the tool to help educate children about the risks of communicating with strangers online and this was one of the purposes of the high school activity in Cumbria that forms the basis of my analysis below.

\section{Children as social actors or objects of research in need of protection? High school children's participation in an educational research activity for the project}

The 'Who are you talking to?' activity involving children and young people in years 713 at a Cumbrian high school took place in $2010 .^{4}$ The project researchers initially sought to adopt an approach to the activity that would reflect the 'children as social actors' theoretical perspective, but following consultation with the school, it became evident that this would have to be modified, as will be explained below. Immediately prior to taking part, the children were told in broad terms that the activity was about using the internet and how people chat online and that when the activity had finished, they would have a de-briefing session. During the activity, the children chatted to adults and children (sat at computers in another room) in specially created chat rooms for fifteen minutes. They were given a sheet of paper explaining a problem the person they would be chatting to had (for instance, they were struggling to find time to revise for their exams because of a part-time job). They then chatted to this person about the problem, although they were encouraged to talk about anything they liked. The process was repeated with another behind the scenes participant with a different problem. At all times, there was a teacher and/or a researcher present in the room with the children. 
At the de-briefing session, the children were asked to complete a form online which included questions regarding who they thought they were communicating with during the activity and how they came to their decisions. Significantly, when the children were talking to adults pretending to be children, they only correctly guessed that they were communicating with an adult $18 \%$ of the time. In marked contrast, the Isis software tool was $94 \%$ accurate in these cases. For each of the children, the teacher revealed one of the identities of the people whom they talked to (whether they were an adult or child and their gender), and the children were provided with a further explanation of what the study was about. This generated discussion about whether they would talk to strangers online. The teacher reminded the children which person was the school's child protection 'link' or whom they could talk to if they had further questions. The child protection dimensions of the project generated media interest; part of the activity was filmed and some of the children were interviewed for a BBC News report (BBC, 2010).

\section{Consent and gatekeeper requirements}

Parental consent was sought for children's participation. The project researchers gave the school an information sheet for parents containing a project overview, details about what the activity would involve and its aims and intended outcomes, and links to the project website to enable parents to find out more information should they wish to. The school then communicated with parents to let them know about the study and that their children may be taking part in it, provided them with the information sheet and informed them to contact the school if they did not want their children to take part. Thus, the study involved an opt-out method of obtaining consent from parents - that is, the parents needed to inform the school if they did not want their children to take part. There are concerns that opt-out methods of obtaining consent are less ethically 
defensible than opt-in methods because they are more intrusive (Alderson and Morrow, 2004, p. 46). Notably, however, the NBC does consider that opt-out arrangements might be appropriate (albeit in the context of seeking parental consent to contact a child), and has emphasised that "we would always follow the requirements and protocols of the setting in which we were doing the research' (NBC, 2009, p. 6). This was certainly the case in the context of the Isis activity - the opt-out approach to obtaining parental consent for the activity was at the school's behest. One particular ethical issue this approach to obtaining consent raises is that parents might have been less likely to object to their children's involvement because the school was supportive of the research, especially because internet safety is emphasised as being important to the school in regular newsletters sent out to parents.

That the project researchers had to go through a gatekeeper (the school) inevitably impacted on the options available regarding the consent process (see also Gallagher and others, 2010). The school preferred to make parents the primary consent gatekeepers. This approach is far from uncommon (Heath and others, 2007), harking back to the more traditional theoretical approach of perceiving children as objects rather than as subjects in the social world. The school's decision to prioritise parental rather than children's consent was also made in part because the activity was perceived as being as much of an educational activity for the children as a research study. It was carried out within a personal, social and health education class. Researchers were aiming to assist in educating children as to the risks of online communications with individuals they do not know, but were also seeking valuable data that would be used to inform the development of the Isis technical tools. As such, the aim of the exercise was twofold; to educate children and to gain knowledge from their participation. This represents a 
problem because research and educational activities work within their own boundaries and frameworks. A research activity taking place in a school setting is subject to contemporary ethical norms regarding informed consent, however an educational activity in a school setting is subject to educational norms that do not demand informed consent to participate, but rather, an expectation that children will take part. Edwards and Fowler have drawn attention to the concern that "we may frame issues in educational terms when more appropriately they should be framed in other ways' (Edwards and Fowler, 2007, p. 117). It may have been the case that the ethical imperative to obtain informed consent from the children who participated (especially prominent within the 'children as social actors' perspective which the researchers were initially drawn to), was perceived as less of an imperative because of the educational framing of the activity. Such an approach may not be problematic if we are persuaded by Harris' contention that we all have a moral obligation to take part in research, an obligation which Hagger has argued may extend to children (Harris, 2005; Hagger, 2009, pp. 188-9). If it is accepted that this is the case, the need to obtain consent from children to participate in research might come to be seen as less crucial. However, this could exacerbate the concern that children (or parents) feel unable to dissent because of the expectation that they will participate.

Notwithstanding the priority attached to consent from child participants in contemporary approaches to involving children in research that emphasise the child as a social actor, there can be an important reason in favour of prioritising parental over child consent. It has been recognised that when children are invited to participate in research that takes place at school, they may feel compelled to take part because it is not the norm for them to have the option of opting out in this environment (Morrow and 
Richards, 1996, pp. 101-102). With this concern in mind, the researchers and teachers accepted that children could refuse to participate.

What information needed to be divulged to sufficiently inform the children?

A particular dilemma the researchers faced was how much information needed to be communicated about the project in order to ensure that the children participating were sufficiently 'informed'. According to Save the Children, 'All those involved, especially the children, need to be clear about the purpose of their participation - what it involves and what impact it may have.' (Save the Children, 2003, p. 6.) The children were informed about the overall purpose of their participation (to contribute to a project about safety online), what their participation involved (chatting for fifteen minutes to someone they did not know within the boundaries of school safety procedures) and what impact it might have (contributing to the development of tools to help children stay safe online). However, the Isis project researchers had distinct problems to contend with on the matter of the technical operation of the software programme. The tool is a covert device designed to assist in law enforcement related to child protection; revealing too much about it could have impacted on its effectiveness in enhancing child protection online. Furthermore, explaining the way in which the tool operates would have meant providing the children with technical information that could have led to them becoming overloaded, causing confusion and/or boredom. This is not just a matter of concern because the participants were children; any lay person would have had difficulty understanding the technical information pertaining to algorithms etc. As such, the project highlights a boundaries of consent issue regarding technical knowledge which is relevant to much technical and clinical research. For the Isis project, a middle ground position between the theoretical 'children as social actors' approach to doing research 
and the broader public (child protection) interest in the future effectiveness of the tool was opted for: children were told in broad terms about the nature of the research and its aims of offering better protection to children online - no specific information about the tool was divulged. The same approach was taken in the information sheet sent out to their parents.

\section{Protection of confidentiality}

Data protection concerns and the balancing of such concerns with child protection in the context of the Isis project have been noted elsewhere (Watson and others, 2009). With specific regard to the use of children's data from the high school activity, in order to have the pupils' chat data released to the project team by Cumbria and Lancashire Education Online (CLEO), ${ }^{5}$ a letter and contract were completed and signed. A confidentiality agreement was also signed between the chief investigator of the project and the school. The school set up the environment in which the activity took place. Each child was given a user account that had no connection to them, for example, G2S2 (group 2, student 2). These usernames were in the chat data and the only information the researchers were given was the age and gender of the pupil. Thus any child data from the study that has been used in the project to train the software tool was already anonymised before it was received by the researchers. Consequently, ethical concerns relating to confidentiality were met and legally, as the data used is non-identifying, the DPA does not apply.

It is also important to consider confidentiality concerns pertaining to children's disclosure of information. A potential outcome that might have occurred is that one of the children participating in the activity could have disclosed that $\mathrm{s} / \mathrm{he}$ was in contact 
with someone online who s/he had concerns about, but stated that $\mathrm{s} / \mathrm{he}$ did not wish this information to be revealed to anyone else. In such a situation, if the disclosure had been made to one of the researchers, s/he would have sought the teacher's advice. If the teacher considered the child to be at risk of harm, then s/he would have been under a duty to inform the member of staff with particular responsibility for child protection (see generally Department for Children, Schools and Families, 2010), but to have discussed the matter with the child and tried to obtain his/her consent first. With regards to the legal position if the child had refused to agree to disclosure, it seems that the child's right to privacy under Article 8(1) of the ECHR could be legitimately overridden on the basis that this was necessary to detect a possible crime. This crime might be, for example, a planned future crime related to sexual abuse of the child. Moreover, as already noted, the child's welfare is of paramount concern generally under English law. If a child had disclosed this information to a researcher but asked her/him not to tell the teacher, although the researcher may not have been under a legal duty to inform the teacher (Williamson and other, 2005), s/he would have felt under an ethical duty to do so if s/he considered the child to be at risk. These are circumstances in which the researchers would have considered it most appropriate to adopt a 'children as objects' approach to doing research. This may have involved them having to make a difficult assessment as to possible harm. However, it is highly unlikely that this situation would have arisen since it was agreed between the researchers and school from the start that there would be a teacher present at all times throughout the activity. Nonetheless, to avoid the perceived breach of trust that this situation could raise, children could have been informed that their confidentiality would be respected unless the matter related to them being at a risk of harm (with clarifying examples being provided). 


\section{Children's own interpretation of the findings}

One of the activity's aims was to educate children as to the dangers of online communications with a stranger. However, this does not necessarily mean that the balance was weighted more heavily in favour of a more paternalistic approach to child protection than children's autonomy rights. If taking part had the effect of better protecting the children involved, this was through educating them in how to make themselves more resilient to attempts to groom them online. Following the 'children as active participants' perspective to involving children in research for this part of the activity, the researchers considered it important that the children were allowed to draw their own conclusions from the findings. They were encouraged to interpret their own data and think through the issues for themselves. Some of the children created their own way of delivering the safety message to other children at the school. They made 'Fakebook' cards which featured smiling teenagers and asked the question 'you think you know who you're talking to?' They placed these on notice boards around school. Thus, a possible benefit of participating in the activity was that the participants and their peers became more aware of the dangers of chatting online to strangers and adapted their behaviour when communicating online as a result. However, I note that benefits of being involved in the activity by way of attitudinal or behavioural changes 'can be hard to define and assess precisely' (Alderson and Morrow, 2004, p. 39).

Significantly, therefore, in the context of this part of the activity, the child protection aim was framed around children's rights to draw their own interpretations and conclusions and act upon these. As such, the researchers tried to achieve the activity's child protection aim in part through recognising children's autonomy rights. 


\section{Conclusion}

Contemporary research ethics prioritises the autonomy rights of children who participate in research. However, the Isis project illustrates that in the context of an educational research activity, there can be tensions between respecting children's autonomy rights and meeting the 'essentially adult centred' requirements of gatekeepers (Balen and others, 2006). Whilst there was a commonality between the ethical guidelines surrounding confidentiality and privacy and the requirements set by the school and CLEO, there was marked discord on the matter of child consent. Whereas this matter is frequently prioritised as a right for child participants in the guidelines, obtaining parental consent rather than (or sometimes alongside) child consent is the norm for participation in an educational research activity which would not usually form a part of the school's normal teaching sessions (Heath and others, 2007). The fact that the aim of the activity was as much educational as research-based was also significant, as this may have encouraged the framing of the activity within educational, institutional norms that assume rather than demand children's consent to participate. It would have been difficult for the project researchers to have adopted a different approach which prioritised child consent over parental consent when this would not have satisfied the gatekeeper. Moreover, it would have been harder to obtain the amount of data needed to help train the Isis tool if the participation of children in a school-based activity had not been sought. Heath and others have suggested that one way to tackle this is for researchers 'to be more insistent upon respecting the rights of children... in institutional settings' (Heath and others, 2007, p. 415), albeit that this is a strategy that may well make some gatekeepers inclined to deny access to children in their care. This raises a 
question pertaining to beneficence and the value of the research: does the value of research outweigh compromising relationships with gatekeepers and thus the ability to do the research in the first place? Moreover, it is reasonable to expect that researchers will be able to change accepted institutional norms? The priority of the gatekeeper's organisation may outweigh all other priorities. An argument could thus be made that governing bodies should at least comment on how priorities should be determined. If governors were to agree that safeguarding should take priority over education, then gatekeepers may take a different position. The intervention of governing bodies may therefore be more effective in challenging institutional norms than researchers taking a firmer stance on prioritising child consent.

A dilemma for the researchers that is more specific to this particular project was balancing on the one hand, the contemporary ethical demand that the children who participated in the activity be informed about the project with, on the other, the level of information that could be provided about the Isis tool without compromising its future effectiveness in enhancing children's safety online. The middle ground position the researchers opted for meant that the children were informed about the broad nature of the project (the development of technologies that could be used to help determine who they were talking to online), without the revelation of more specific information about the workings of the tool.

One especially positive aspect of the research for the researchers was the way in which the children interpreted the findings of the activity and designed their own method of conveying the safety message to their peers. On this matter of active participation and 
encouraging children to draw their own conclusions from the findings, both contemporary research ethics and educational norms were in harmony.

Taking all these issues into account, the activity recognised children as social actors in some respects but in others, especially regarding consent, the gate keeping requirements meant that the more traditional approach of children as objects of research was necessarily adopted. The fact that the activity related to a project framed around child protection may also have encouraged such an approach but as noted, the safety message was conveyed in part through children's own reactions to the interpretation of the findings. Something of a balance was thus achieved between autonomy rights and protection.

To conclude, the existence of varying theoretical perspectives on children's involvement in research, ethical guidelines comprising of a 'mix and match' of these perspectives and the need to comply with institutional norms pose particular challenges for researchers. However, it is important to remember that there is no definitive right answer to the ethical questions that involving children in research raises and no doubt in large part, this is because there continue to be contradictions and tensions in the way that adults perceive children and childhood.

\section{Notes}

1. See http://www.comp.lancs.ac.uk/isis/.

2. Ethical approval for the project was obtained from Lancaster University's Research Ethics Committee. 
3. Grooming can be conceived as a predatory act perpetrated in order to facilitate sexual abuse (Ost, 2009, p. 32-39).

4. I use the term 'children' for the purposes of brevity, however, in the case of the older children who participated, 'young people' is of course the more appropriate term.

5. CLEO provides a private broadband network for all schools across Cumbria and Lancashire.

\section{Acknowledgements}

Thanks to Alistair Baron, Corinne May-Chahal, Awais Rashid, Paul Rayson and James Walkerdine and to the anonymous referees for their helpful comments on earlier drafts of this paper.

\section{References}

Alderson P and Morrow V. 2004. Ethics, Social Research and Consulting with Children and Young People. Barnardos: Ilford.

Balen R, Blyth E, Calabretto H, Fraser C, Horrocks C and Manby M. 2006. Involving Children in Health and Social Research: "Human becomings" or "active beings"? Childhood 13: 29-48.

Biggs H. 2010. Healthcare Research Ethics and Law: Regulation, Review and Responsibility. Routledge-Cavendish: Abingdon. 
BBC News, "New software to "vet" chatroom users', 31 May 2010. http://www.bbc.co.uk/news/10199819 [accessed 25 July 2011].

British Educational Research Association 2004. Revised Ethical Guidelines for Educational Research. BERA: Southwell.

British Sociological Association 2002. Statement of Ethical Practice for the British Sociological Association. BSA: Durham.

Christensen P and Prout A. 2002. Working with Ethical Symmetry in Social Research with Children. Childhood 9: 477-497.

Cree VE, Kay H and Tidsall K. 2002. Research with children: sharing the dilemmas. Child and Family Social Work 7: 47-56.

Department for Children, Schools and Families 2010. Working Together to Safeguard Children. DCSF Publications: London.

Edwards R and Fowler Z. 2007. Unsettling boundaries in making a space for research. British Educational Research Journal 33: 107-123.

Flaskerud JH and Winslow BJ. 1998. Conceptualizing Vulnerable Populations in Health Related Research. Nursing Research 47: 69-78. 
Fraser S, Lewis V, Ding S, Kellett M and Robinson C (eds). 2004. Doing Research with Children and Young People. Sage: London.

Gallagher M., Haywood SL, Jones MW and Milne S. 2010. Negotiating Informed Consent with Children in School-Based Research: A Critical Review. Children and Society 24: 471-482.

Green S and Hogan D (eds). 2005. Researching Children's Experience. Sage: London.

Hagger L. The Child as Vulnerable Patient: Protection and Empowerment. Ashgate: Aldershot.

Harris J. 2005. Scientific research is a moral duty. Journal of Medical Ethics 31: 242248.

Heath S, Charles V, Crow G and Wiles R. 2007. Informed consent, gatekeepers and gobetweens: negotiating consent in child- and youth-orientated institutions. British Educational Research Journal 33: 403-417.

Holland S, Renold E, Ross NJ and Hillman A. 2010. Power, agency and participatory agendas: A critical exploration of young people's engagement in participative qualitative research. Childhood 17: 360-375.

Hughes D, Rayson P, Walkerdine J, Lee K, Greenwood P, Rashid A, May-Chahal C and Brennan M. 2008. Supporting Law Enforcement in Digital Communities through 
Natural Language Analysis. International Workshop on Computational Forensics, Springer Lecture Notes in Computer Science 5158: 122-134.

Morrow V and Richards M. 1996. The Ethics of Social Research with Children: An Overview. Children and Society 10: 90-105.

NCB 2003. Guidelines for Research. NCB: London.

NCB 2009. NCB guidelines for research with children and young people. NCB: London.

NSPCC 2009. Research Ethics Guidance. Available at http://www.nspcc.org.uk/Inform/cpsu/research/commission/researchethics_wdf64298.p df [accessed 25 July 2011].

Ost S. 2009. Child Pornography and Sexual Grooming: Legal and Societal Responses. Cambridge University Press: Cambridge.

Save the Children 2003. Promoting Children's Meaningful and Ethical Participation in the UN Global Study on Violence against Children. Available at www.savethechildren.net/alliance/resources/chpart_childrenviolence.doc [accessed 25 July 2011].

Society for Research in Child Development 2007. SRCD Ethical Standards for Research with Children. Available at 
http://www.srcd.org/index.php?option=com_content\&task=view\&id=68\&Itemid=499 [accessed 25 July 2011].

Royal College of Paediatrics, Child Health 2006. Guidelines for the Ethical Conduct of Medical Research Involving Children. Archives of Disease in Childhood 82: 177-182.

Walkerdine J, Greenwood P, Rashid A, Rayson P, May-Chahal C, Duquenoy P, Watson P, Jones M and Brennan M. 2009. Forensics Software for Detecting Online Paedophile Activity. ICT that makes the Difference, Brussels, 22-25 November 2009.

Watson P, Duquenoy P, Brennan M, Jones M and Walkerdine J. 2009. Towards an Ethical Interaction Design. OZCHI 23-27 November 2009, Melbourne. Available at http://eprints.comp.lancs.ac.uk/2225/1/Towards_an_Ethical_Interaction_Design_06-1009.pdf [accessed 25 July 2011].

Williamson, E, Goodenough, T, Kent, J and Ashcroft, R. 2005. 'Conducting Research with Children: The Limits of Confidentiality and Child Protection Protocols' Children and Society 19: 397-409. 